\title{
A relação entre preço e qualidade: uma contribuição metodológica utilizando lógica fuzzy
}

The relationship between price and quality: a methodological contribution using fuzzy logic

Júlio Rohenkohl

julioroh@gmail.com

Universidade Federal de Santa Maria (UFSM)

\section{Orlando Martinelli}

orlando.martinelli@gmail.com

Universidade Federal de Santa Maria (UFSM)

Resumo: O artigo apresenta uma contribuição metodológica para o estudo da relação entre preço e qualidade das mercadorias. Faz-se um exercício empírico para um produto alimentar. Utiliza-se a teoria dos conjuntos fuzzy para analisar a relação entre a qualidade e o preço das mercadorias, explorando variantes da ótica do consumidor para captar $a$ ) a relevância de características qualitativas para o estabelecimento do preço a pagar e, alternativamente, $b$ ) a relevância do preço como sinalizador de qualidade. Este método aproxima a formalização matemática da manifestação do consumidor, reduzindo a necessidade de pressupostos teóricos inerentes à organização da informação mediante técnicas de variação infinitesimal. O resultado do exercício sinaliza ser o preço um indicador de qualidade das mercadorias, principalmente quando a qualidade torna-se ruim na percepção dos consumidores.

Palavras-chave: Mercadorias; Qualidade; Relações Fuzzy

Códigos JEL: D00; L15; B52.

\begin{abstract}
The article presents a methodological contribution to the study of the relation between price and quality of goods. An empirical exercise is performed for a food product. Fuzzy sets theory is used to analyze the relationship between quality and price of products, exploring variants of the consumer's perspective to capture a) the relevance of qualitative characteristics for the establishment of the price to be paid and, alternatively, b) the price relevance as a quality flag. This method approximates the mathematical formalization to consumer manifestation, reducing the necessity for theoretical assumptions inherent to the organization of information through infinitesimal variation techniques. The result of the exercise signals that the price is an indicator of the quality of the merchandises, especially when the quality becomes poor in the perception of the consumers.
\end{abstract}

Keywords: Merchandises; Quality; Fuzzy Relationships

JEL Codes: D00; L15; B52.

Recebido em: 14-03-2018. Aceito em: 28-05-2018. 


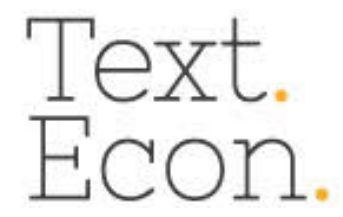

\section{INTRODUÇÃO}

A visão mais convencional de microeconomia estabelece que a determinação do preço de uma dada mercadoria ${ }^{1}$ normal é regida por dois constructos básicos: a lei de oferta e demanda e o princípio da escassez associada à utilidade marginal dessa mercadoria. No plano analítico individual, o sujeito econômico é capaz de ordenar, sem ambivalências, qualquer número de mercadorias de acordo com as suas preferências individuais. As variações de qualidade são perfeitamente distinguidas e compreendidas. Cada sujeito, no entanto, percebe uma utilidade diferente para cada mercadoria qualitativamente distinta das demais, baseado em suas preferências individuais. Assim, por exemplo, a manifestação de um aumento da demanda relativamente à oferta induz logicamente a uma elevação do preço a ser pago por quantidades adicionais, dada a maior percepção de escassez relativa da mercadoria associada ao seu mapa de preferências. É possível derivar a sua curva de demanda individual e estabelecer o preço relativo a outras mercadorias. Deste modo, cada mercadoria apresenta uma única relação entre preço e quantidade demandada ou ofertada. Uma variação qualitativa em uma mercadoria, a rigor, origina outra relação entre preço e quantidade.

No plano analítico agregado do equilíbrio geral, a qualidade das mercadorias de um mesmo mercado ou indústria é suposta como homogênea ou idêntica entre as diversas unidades, e o mix de tipos (indústrias) é constante. O ajuste de oferta e demanda que determina o equilíbrio do mercado ocorre em função do preço e da quantidade da mercadoria. A qualidade da mercadoria é bem estabelecida entre os demandantes e ofertantes, bem como é um elemento constante no tempo transacional de mercado. O preço sinaliza perfeitamente a escassez ou a abundância relativa da mercadoria e permite a coordenação das decisões descentralizadas de diversos agentes que participam do mercado.

Simetricamente à face da demanda dos consumidores, o lado da oferta das firmas na teoria econômica incorpora a mercadoria homogênea, a informação perfeita e as decisões sem ambivalência, focalizando a atenção em variações marginais nos custos. A partir dos anos de 1920, uma série de contribuições teóricas e empíricas voltadas para o funcionamento da firma e para a concorrência entre firmas em um plano industrial propôs argumentos que desafiaram

\footnotetext{
${ }^{1} \mathrm{O}$ uso recorrente das palavras "mercadoria" e "produto" como equivalentes, em que pese sacrifício de estilo, objetiva evitar conotações subjacentes a "bem" e "commodity", a primeira palavra ligada a avaliações marginais de utilidade e a última à presunção de homogeneidade qualitativa dos itens produzidos e transacionados.
} 


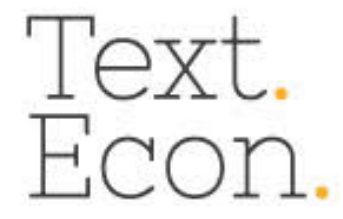

modelos de concorrência baseados no mercado perfeito (SRAFFA 1982, HALL\&HITCH 1986, STEINDL, 1983). Essas contribuições foram marcantes para a teoria econômica entre as quais se destacam: a) o estabelecimento de uma fragilidade da estrutura de custos da teoria neoclássica, comprometida com o equilíbrio da firma, e desafiada por estudos empíricos; $b$ ) a inadequação, diante da constatação de interação entre firmas no processo concorrencial, da polarização em concorrência perfeita ou monopólio como marcos de interpretação de mercados industriais; e $c$ ) a aceitação de que as armas de concorrência utilizadas pelas firmas são muitas, não se limitam apenas a preços e abarcam publicidade, inovação tecnológica e qualidade das mercadorias.

Destarte, na economia real, o que se verifica é o surgimento, cotidiano, de mercadorias com diferentes características qualitativas de natureza estética, ergonômica, socioeconômica, cultural, etc.. Este artigo, em linha com a reinterpretação da concorrência industrial do século passado, entende que a mercadoria não deve ser concebida em $x_{\mathrm{i}}$ qualidades estáticas e perfeitamente determinadas no mercado. Parte-se de uma visão dinâmica de mercado, em que o processo concorrencial (lato sensu) é de fundamental importância para a geração de estímulos endógenos à criação de diferenças qualitativas das mercadorias. Nessa perspectiva, as alterações de qualidades estão, em geral, associadas a mudanças nos processos produtivos de características também novas. Indústrias apresentarão a introdução de novas variedades de produtos, implicando mudanças qualitativas das mercadorias, seguidamente entrelaçadas com correspondente alteração do processo de produção e de organização das firmas. A qualidade não só aumenta ou diminui, novos atributos surgem, dificultando a comparação do que é bom ou ruim. Numa terminologia da microeconomia tradicional, os mapas de curva de indiferença dos consumidores e suas respectivas utilidades ficariam nebulosos.

$\mathrm{Na}$ visão de concorrência que inclui atributos exceto-preço, a convergência do preço associado a uma definição qualitativa de mercadoria fica difícil, uma vez que o próprio parâmetro de qualidade pode ficar obsoleto, ou seja, a unidade do que seja o produto ou as qualidades relevantes muda. Mais do que isto, os preços adquirem um papel no processo de concorrência entre as firmas que não está relacionado logicamente à convergência de equilíbrio do mercado. Preços são variáveis atreladas ao processo de acumulação de longo prazo das firmas, da busca do lucro não estritamente maximizador e, assim, não se relacionam apenas com a escassez da mercadoria.

Do lado dos consumidores, a evolução de valores, as manifestações socioculturais, a projeção de status social pelo consumo e o aprendizado de consumo também introduzem 


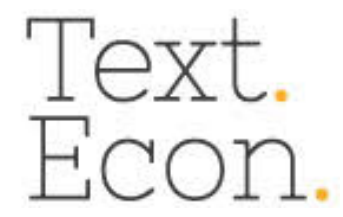

novas perspectivas de avaliação das características das mercadorias. O aprendizado de consumo não envolve necessariamente o conteúdo e a maneira de fabricação dos produtos, mas a exploração de novos serviços das mercadorias. Indivíduos podem manifestar diversas necessidades e desejos que são satisfeitos parcialmente por diferentes inputs (serviços das mercadorias) que satisfazem indiretamente diversas necessidades e desejos. O aprendizado implica o consumidor explorar novos serviços disponibilizados por uma mercadoria. Todos estes elementos levam a uma não saciedade do consumo de certas mercadorias (WITT, 2001 e 2016). ${ }^{2}$

Os defensores dos equilíbrios de mercado poderiam argumentar que seria preciso deixar o tempo transcorrer até que as "forças do mercado" estabeleçam critérios claros de qualidade dos produtos implicados no processo concorrencial. Isso pode ser, logicamente, verdadeiro. Objetivamente, no entanto, quanto tempo seria necessário para isso ocorrer? Por outro lado, poder-se-ia pensar, também logicamente, que mesmo antes do processo de clearing terminar, as "forças da oferta de mercado" (lato sensu) podem provocar e modificar endogenamente e dinamicamente os sentidos e o aprendizado de uso dos consumidores das mercadorias de uma empresa, bem como o aprendizado de oferta de "seus concorrentes". Isso alteraria - através de novas mercadorias e com distintas combinações de características e serviços -, o ordenamento das preferências, impossibilitando a determinação de um "preço de equilíbrio" que capte diretamente o valor monetário e sua correspondente qualidade.

A questão que surge, então, é como avaliar objetivamente os atributos da qualidade de um produto (e seus possíveis reflexos nos preços) se eles não são universais (avaliados por todos da mesma forma), nem homogêneos (iguais entre os produtos de uma mesma classe ou grupo industrial), e nem estáveis ao longo do tempo? Sem ter a pretensão de se exaurir o assunto, dada a complexidade do tema, este artigo procura, introdutoriamente, dar conta de uma aferição da relação entre qualidade e preço das mercadorias.

Propõe-se a elaboração de uma ferramenta metodológica que ajude a captar e organizar as diversas percepções que o consumidor possui sobre os atributos de uma mercadoria, e como eles podem se manifestar nos seus planos de decisões de consumo. Esta ferramenta - apresentada na forma de um exercício empírico elementar - é amparada na

\footnotetext{
${ }^{2}$ Por exemplo, se a energia fornece aquecimento e cozimento de alimentos, quando alguém está aquecido possivelmente ainda quererá cozinhar e continuará a consumir a energia; e quando estiver sem fome, poderá continuar consumindo energia para cozimento porque aprendeu que o cozimento altera texturas e sabores, fato que lhe proporciona satisfação no consumo de pequenas porções de alimento. O consumidor aprende a extrair outros serviços de um mesmo item.
} 


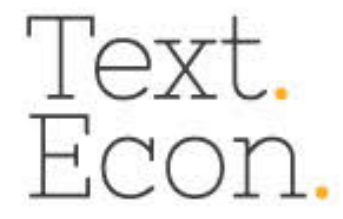

lógica fuzzy e na teoria dos conjuntos fuzzy, que permitem operacionalizar objetivamente avaliações humanas impregnadas de valores e incertezas a respeito de diversos atributos simultaneamente presentes em uma determinada decisão. Com o intuito de obter maior simplicidade analítica, o exercício empírico investiga a decisão de compra de uma mercadoria menos complexa em seus atributos (escolheu-se uma mercadoria alimentar básica) pautada pela influência da possível variação da relação preço- qualidade da mercadoria.

Após esta introdução, apresenta-se uma exposição de diversas concepções que o aspecto qualitativo de produtos teve em teoria econômica. A terceira seção dirige a atenção para a percepção de consumidores acerca da qualidade de mercadorias alimentares. Logo a seguir, definem-se lógica, conjuntos e relações fuzzy, bem como se desenvolve uma aplicação das mesmas para a relação entre preço e qualidade segundo as percepções de consumidores do corte de carne bovina picanha. Ao final do artigo, discutem-se os resultados do exercício. Eles convergem com argumentos anteriores de Chamberlain (1953). Obviamente que não se reivindica a generalização de um exercício. No entanto, o resultado abre caminho para outro tratamento formal do problema, mostrando a aplicabilidade de uma alternativa que supera a ancoragem de um fazer científico comprometido com a precisão infinitesimal.

\section{PREÇO, QUALIDADE E CONCORRÊNCIA: A MERCADORIA COMO UMA VARIÁVEL ECONÔMICA}

A abordagem microeconômica neoclássica ficou praticamente incólume a críticas até meados dos anos de 1920. Porém, o conceito de concorrência perfeita e o axioma de homogeneidade das mercadorias são fortemente criticados especialmente a partir das contribuições de Sraffa (1982), de Joan Robinson (com a sua teoria de concorrência imperfeita, publicada em 1933) e Edward Chamberlain (com a sua teoria de concorrência monopolista, também publicada em 1933), cujas obras evidenciam a irrelevância da hipótese de relação unívoca e estável entre o preço da mercadoria e sua qualidade, implícita da microeconomia tradicinal, para compreender os efetivos processos de escolhas.

Notadamente para Chamberlain $(1953,2)$, a incorporação da evidente heterogeneidade dos produtos transforma e engrandece a teoria econômica. "A concorrência exceto preço"3, que envolve diferenciais de qualidade nos produtos e publicidade, é inconsistente com o modelo de concorrência perfeita. A quantidade vendida de um produto depende em parte do

\footnotetext{
${ }^{3}$ Tradução livre para "Non-price competition".
} 


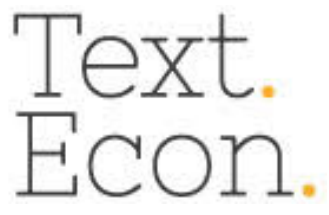

preço solicitado e em parte dos atributos do produto e do montante gasto em persuadir o cliente. O produto é uma composição de inúmeros aspectos, tais como localização, tamanho, desenho, valor nutritivo, habilidade manufatureira, entre outros. Os produtos são o elemento mais volátil do sistema econômico - muito mais instáveis que os preços (Chamberlain, 1953, $3-8)$.

Conforme Chamberlain $(1953,6)$, é elemento do senso comum de que há uma forte correlação entre a qualidade do produto e seu preço, embora a análise convencional da concorrência restrinja-se a variação de preços para produtos dados (homogêneos entre si e constante no tempo de análise).

\footnotetext{
If products were actually "given", people would rush to buy from the seller whose price was cheaper because they would know they were getting the same thing for less money. Since products in the real world are not "given", people will naturally recognize that the lower price may be accompanied by poorer quality and their response to it will be diminished; it may be negative. (Chamberlain, 1953, p. 6).
}

As contribuições de Robinson e Chamberlain repercutiram. Segundo Lupton (2015, 512), há dois agrupamentos de trabalhos de economia do pós-II Guerra que discutem qualidade das mercadorias. O primeiro debate a qualidade como um problema de assimetria de informação. O segundo grupo explora o compartilhamento da incerteza qualitativa entre os agentes econômicos.

Dentre as investigações da qualidade como assimetria de informação, destaca-se o trabalho de Akerlof (1970). Nesta abordagem, admitem-se dificuldades de objetivação da qualidade da mercadoria decorrentes da assimetria de informações e da incerteza inerente à avaliação qualitativa de bens e serviços transacionados nos mercados. As aplicações da teoria de Akerlof (1970) se limitam a situações que combinam assimetria de informações e desonestidade. A teoria não pode ser estendida a casos de dinâmica industrial na qual, em diversos segmentos e em diferentes graus, há a criação deliberada de diferenciais qualitativos nas mercadorias em meio a processos concorrenciais regidos pelo lucro extraordinário e sobrevivência em longos horizontes de tempo. A redução da variação qualitativa à dicotomia bom ou ruim decorrente da assimetria de informações enquadra o problema teórico na potencialidade de resolução das variações marginais infinitesimais e da classificação binária.

A contribuição de Stiglitz (1987, 9-11) também avançou no tema preço-qualidade ao romper com a chamada "Lei do Preço Único", e conceber explicita e formalmente o preço como sinalizador da qualidade e, também, dois preços (salários ou taxas de juros) atrelados à 


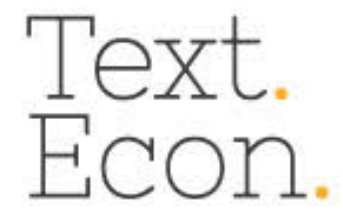

mesma quantidade (de produtividade do trabalho ou retorno dos empréstimos), porém pagos a grupos qualitativamente diferentes (de trabalhadores ou de tomadores de empréstimos). Sua discussão, no entanto, limita a variação qualitativa a risco moral e seleção adversa nos mercados de trabalho, de seguros e de capitais. Sua extensão ao mercado de produtos (1987, 23) não incorpora os aspectos endógenos e multifacetados (vários atributos qualitativos na mesma mercadoria) inerentes ao processo de concorrência entre as firmas e à diversidade avaliativa dos consumidores. A qualidade permanece dicotômica, ou a mercadoria é de boa qualidade ou é de má qualidade.

Um segundo grupo de trabalhos discute situações nas quais todos os agentes compartilham a incerteza de qualidade. Lupton $(2015,512)$ apenas menciona Albert Hirschman (1973) e ela mesma neste grupo. No entanto, há uma literatura mais ampla que contribui para esta perspectiva. Um autor importante é Scitovsky (1944), que introduz a relação do preço pago pelo consumidor como o status proporcionado pelo consumo da mercadoria.

Identificou-se um terceiro grupo de estudos que, na linha de Chamberlain, tentou formalizar a relação entre preço e qualidade. Tais modelagens para incorporar a "concorrência exceto em preços" decorrem de esforços de economistas como H. Brems (1951 apud KOUTSOYIANNIS, 1982) em sua obra Product Equilibrium under Monopolistic e L. Abbott (ABBOT 1955 apud KOUTSOYIANNIS, 1982) em seu livro Quality and Competition. O que fica claro nestes modelos é a tentativa de incorporar a variação de qualidade em harmonia com o instrumental de variações marginais de custos e de receitas. A relação entre a qualidade e os preços seria esclarecida pelo ajuste do mercado. O equilíbrio manteve-se como referência no estabelecimento do preço exato e da quantidade precisa da operação da firma no mercado. Para tanto, a incorporação teórica da variação de qualidade das mercadorias implicou reformas tímidas, mantendo-se a maioria dos supostos consolidados nos modelos de mercado perfeito, tais como: $a$ ) custos em forma de "U", $b$ ) livre entrada e saída de firmas, $c$ ) perfeito conhecimento das opções de produção (qualidade, tecnologia), e $d$ ) as firmas têm um único produto.

O comprometimento com o estabelecimento de um ponto preciso de equilíbrio deixa pouco espaço de manobra para compreender o processo de valoração das variações de qualidade, processo este que, pela ótica da concorrência entre as firmas, é justamente concebido como elemento desorientador dos parâmetros de mercado com o intuito de abrir espaços de renda extraordinária. Presa aos cânones teóricos clássicos e aos instrumentos de 


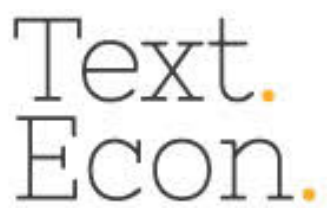

mensuração precisa, não surpreende que a linha de investigação de modelos neoclássicos com concorrência em qualidade tenha sido incapaz de dar conta de uma faceta da realidade que reiteradamente remexe e turva o ambiente econômico.

A turbidez do ambiente pode confundir a análise. A próxima subseção apresenta uma classificação das variações qualitativas que auxilia a organizar as variações de qualidade e a perceber a sua importância nas decisões dos agentes econômicos.

2.1 A classificação da qualidade

Há três tipos de variação de qualidade: vertical, horizontal e inovativa (KOUTSOYIANNIS, 1982).

A qualidade vertical diz respeito a graus de qualidade associados a diferenças em custos; a qualidade superior implica custos mais elevados de fornecimento. Abarca diferenças objetivamente quantificáveis em algum material ou atributo técnico. Elevações de qualidade implicam maior quantidade de um certo material, adição de um serviço ou uso de técnica mais apurada que levem a custos de oferta superiores. São exemplos os voos comerciais sem serviços de bordo (low cost) ou com o acréscimo de serviço de bordo, e a espessura do aço (KOUTSOYIANNIS, 1982; COESTIER E MARETTE, 2009).

A qualidade horizontal implica variações em atributos que nem sempre possuem correspondência em custos de oferta, e se neles repercutem, a oscilação é de pequena monta. Como exemplos têm-se cor, desenho, estilo, textura e sabor. Em uma diferenciação horizontal, a um preço igual não existe uma classificação única para os consumidores, os quais estabelecem ordens diferentes conforme a sua subjetividade; o mesmo preço pode estar sinalizando qualidades horizontais distintas. As qualidades não são objetivamente piores ou melhores, elas são mais talhadas aos gostos de um certo agrupamento social. Elas relacionamse mais a características das mercadorias que exploram valorações potenciais derivadas das circunstâncias sociais e valores dos consumidores (KOUTSOYIANNIS, 1982; COESTIER E MARETTE, 2009).

A qualidade inovativa, por sua vez, implica a criação de novos requisitos de qualidade inexistentes em versões anteriores da mercadoria, ou à criação de um produto radicalmente novo. O caráter da qualidade inovativa é que ela torna obsoletos os padrões anteriores de avaliação do produto. Pode ou não implicar variações nos custos, e quando afeta custos, nem sempre é para maior (KOUTSOYIANNIS, 1982).

As variantes de qualidade elencadas não são mutuamente exclusivas. 


\section{A QUALIDAdE EM PRODUTOS Alimentícios: A PERCEPÇÃo dOS CONSUMIDORES}

Após a discussão da seção anterior, desenvolvida a partir da perspectiva da firma e da concorrência industrial entre firmas, torna-se muito simplista a hipótese de se relacionar produtos com suas características qualitativas definidas e estáveis. Chamberlain $(1953,9)$ argumentou que se procurarmos nas matérias-primas, talvez algumas fornecidas diretamente pela natureza possam ser classificadas como homogêneas, por exemplo, algum mineral. Porém, mesmo nos produtos agrícolas básicos a qualidade pode variar significativamente; por exemplo, a qualidade da carne oscila conforme a seleção genética e a alimentação dos animais.

Produtos derivados de carne, mesmo com baixa elaboração como os cortes in natura, apresentam variação qualitativa a partir das práticas produtivas. Aos desenvolvimentos dos insumidores da produção animal e da indústria frigorífica que alteram as mercadorias da indústria de carnes (MARTINELLI JÚNIOR et alii, 2014), somam-se as percepções dos consumidores. No entanto, para uma série de produtos alimentares os consumidores não sabem automaticamente a qualidade do produto, ou a precisão das informações fornecidas sobre as características do produto é assimétrica. A gravidade do problema depende do grau de assimetria de informação e de conhecimento.

A abordagem da "qualidade percebida" (perceived quality) tem como foco o processo de percepção de qualidade pelos consumidores e como estes fazem julgamentos sobre a qualidade de um produto quando eles são informados de forma imperfeita. Para isso, esta abordagem considera a influência de variáveis pessoais e situacionais sobre o processo de percepção de qualidade. Existem muitas definições de "qualidade percebida", mas a definição mais reconhecida é "adequação ao uso" (fitness for use), que associa a qualidade e a percepção do consumidor com diversos atributos, tais como durabilidade, salubridade, aparência, marcas conhecidas, gosto, preço e valor nutricional.

O problema do grau de informação assimétrica e a percepção dos consumidores é tratado pelo trabalho clássico de Darby e Karni (1973). Esses autores elaboram uma tipologia que distingue e capta três conjuntos principais de atributos do produto. Os atributos de "pesquisa" (search) são aqueles que os consumidores podem avaliar antes de comprar (por exemplo, a quantidade de gordura da carne). Neste caso, não há informação assimétrica para os consumidores. Os atributos da "experiência" (experience) são aqueles para as quais os 


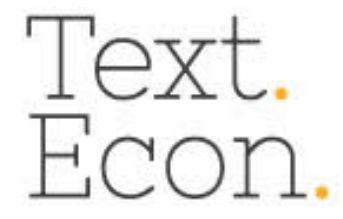

consumidores podem avaliar a qualidade só depois do consumo de um produto (por exemplo: a maciez da carne). Neste caso, mesmo se ex-ante não há informação assimétrica, o consumidor somente aprende ou conhece a verdadeira qualidade ex-post. Por sua vez, os atributos de "confiança/crença" (credence) são aqueles para as quais o consumidor pode não ter informação mesmo consumindo o produto (por exemplo, se uma carne tem hormônio além do permitido).

Em certa medida, a distinção entre os atributos de "pesquisa", "experiência" e "confiança" foi incorporada pela vertente teórica dos modelos de multiatributos que, em geral, fazem a distinção dos atributos do produto em intrínsecos e extrínsecos. Atributos intrínsecos referem-se aos atributos do produto físico - tais atributos não podem ser mudados sem se mudar a essência do próprio produto. Os atributos extrínsecos se referem aos demais (exemplos de atributos extrínsecos são a marca, o preço, o tipo de loja, etc.). Embora tais modelos sejam utilizados em diversos estudos sobre o comportamento do consumidor no campo do marketing, eles fornecem apenas uma visão limitada da qualidade no processo de percepção. Possíveis relações entre atributos não são levadas em conta - por exemplo, que um atributo, como a saúde, pode ser inferido a partir de outros, por exemplo, teor de gordura - e, mais importante, não consideram por que certos atributos contribuem positivamente para a avaliação global, enquanto outros não.

Um avanço nesse sentido está nas denominadas abordagens hierárquicas para análise da qualidade subjetiva, onde o modelo de cadeia de meios-fim (means-end chain model) é o mais desenvolvido (VALETTE-FLORENCE, 1998). Este modelo estabelece que a percepção subjetiva do produto dos consumidores é estabelecida por associações entre os atributos do produto e categorias mais abstratas e cognitivas (tais como valores sociais e psicológicos), que podem motivar um comportamento e criar interesse para os atributos do produto. $\mathrm{O}$ atributo do produto não é relevante por si mesmo, mas apenas na medida em que o consumidor, ao lhe dar atenção, induz a uma ou mais consequências desejáveis ou indesejáveis. A relevância e a conveniência destas consequências são, por sua vez, determinadas por valores do consumidor.

O consumidor é motivado a escolher um produto que lhe proporcione consequências desejáveis, contribuindo e convergindo para a realização de seus valores pessoais e/ou de seu grupo social. Por exemplo, o atributo de um produto "light" está ligado à consequência de consumo "ser magro", que pode, por sua vez, levar à obtenção de valores importantes pessoais e sociais, tais como elevar a autoestima e a visão de terceiros a seu respeito. Um outro 


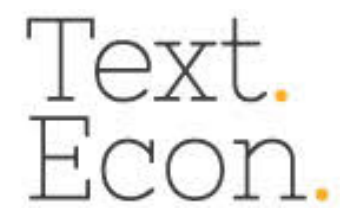

exemplo: um consumidor ao inspecionar e valorizar a cor da carne (uma característica do produto) acredita que a cor está relacionada com o melhor sabor da carne quando preparada (uma qualidade esperada), e esse gosto vai levar a "alegria" ao comer a carne (um motivo abstrato para se comprar) (BRUNSO et alii, 2002).

Nessa perspectiva, a questão da qualidade das mercadorias - associada aos seus $n$ atributos- e a eventual objetivação dessa qualidade em um parâmetro que capte suas dimensões e/ou níveis em um mercado, derivam de cognições de pessoas sobre as mercadorias, em geral normatizadas pela avaliação coletiva - os sujeitos em posição de tomar decisões sofrem diversos tipos de pressão sociocultural e psicológica seletivas para a suas avaliações e escolhas (HODGSON, 1998).

A diversidade de atributos qualitativos e a assimetria de conhecimento tornam a avaliação da relação entre preço e qualidade substancialmente incerta ${ }^{4}$ para todos os agentes envolvidos, até mesmo para os vendedores. A diversidade de qualidade dos produtos rivais, e a de percepção de qualidade dos agentes, impedem que se efetue um cálculo de risco provável acerca da qualidade das mercadorias novas. Essa concepção difere, por exemplo, do modelo de Akerlof no qual a objetividade da qualidade, na verdade, permanece, na medida em que há uma relação única entre preço e qualidade, e a qualidade da mercadoria nova é simplificada à dicotomia "boa" ou "ruim".

Entende-se aqui que as avaliações humanas impregnadas de valores e incertezas a respeito de diversos atributos simultaneamente presentes em uma mercadoria tendem a ser efetuadas de forma verbal através de classificações graduais, e não de forma binária. O uso da expressão verbal permite uma maior aproximação à percepção do sujeito comparativamente ao uso da linguagem matemática alicerçada na lógica binária. Conforme Zimmermann (1991), a linguagem cotidiana ou "natural" é um subconjunto da compreensão humana, porém representa uma parcela maior da compreensão humana comparativamente à linguagem lógica dicotômica (verdadeiro ou falso), mais limitada em sua capacidade de expressão.

Um recurso metodológico objetivo para tratar de situações ambíguas em que os critérios de separação e pertencimento a conjuntos não estão claros, seja devido à grande quantidade de informação a ser processada ou à incerteza presente na situação, é o uso da teoria dos conjuntos fuzzy. Essa teoria é capaz de traduzir a linguagem cotidiana para graus de associação a um conjunto matematicamente definido, e com isso, aproxima a linguagem

\footnotetext{
${ }^{4}$ Esta incerteza não é de probabilidade de ocorrência de um evento, mas de classificação qualitativa do evento.
} 


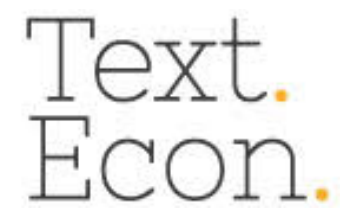

lógica e matemática da linguagem cotidiana, permitindo uma representação organizada mais próxima da riqueza da compreensão humana.

\section{CONJUNTOS FUZZY}

A teoria dos conjuntos fuzzy é alicerçada na lógica fuzzy. Ao contrário da lógica clássica, que tem somente dois valores, verdadeiro ou falso, a lógica fuzzy é multivalorada. Ela traduz expressões linguísticas a um conjunto verdade que pode ser infinitamente valorado entre 0 (falso) e 1 (verdadeiro). Em essência, o que os conjuntos e a lógica fuzzy oferecem é uma ferramenta para aproximar a tradução de palavras para números.

A teoria dos conjuntos fuzzy permite lidar com problemas em que a imprecisão não resulta do comportamento aleatório das variáveis, mas da ausência de critérios claramente definidos de pertencimento (de uma observação ou indivíduo) a um determinado conjunto. As variáveis linguísticas (palavras ou sentenças) podem assumir valores cujos graus variam entre pertencimento absoluto, pertencimento parcial e não-pertencimento.

Um conjunto fuzzy é definido matematicamente por meio da atribuição de um valor que representa o grau de pertinência (ou pertencimento) ao conjunto de cada indivíduo no universo de discurso. Este grau de pertinência representa a semelhança deste indivíduo ao significado que dá identidade ao conjunto. Em termos formais tem-se: Um conjunto fuzzy $A$ é caracterizado por uma função de pertinência $\mu_{A}(x)$, a qual associa a cada elemento de um domínio, espaço ou um universo de discurso $\mathrm{X}$, um número real no intervalo unitário $[0,1]$. $\mathrm{O}$ valor de $\mu_{A}(x)$ em $\mathrm{X}$ representa o grau de pertinência de $x$ em A (ZADEH, 1965). Um conjunto fuzzy representa uma coleção de objetos com valores associados entre 0 (exclusão completa) e 1 (associação completa). Os valores associados expressam o grau com o qual cada objeto é compatível com as características ou propriedades da coleção.

As funções de pertinência associadas aos conjuntos fuzzy dependem não somente do conceito a ser representado, mas também do contexto no qual são usadas. As funções podem ter diferentes formas funcionais. Uma das funções de pertinência mais simples é a triangular. As funções de pertinência são representações equivalentes dos conjuntos fuzzy, e as operações básicas de interseção, união e complemento são representadas tomando o mínimo, máximo e complemento das funções. Estas operações são chamadas operações fuzzy padrão. 


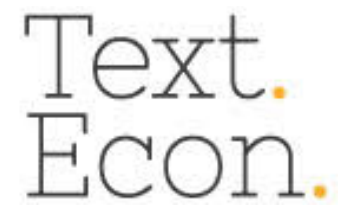

http://dx.doi.org/10.5007/2175-8085.2018v21n2p92

\subsection{Relações Fuzzy}

Um elemento muito interessante presente no trabalho de Akerlof (1970), mas não desenvolvido de forma clara, é de que seu raciocínio propõe que a demanda por carros usados é função do preço $(p)$ dos mesmos e de sua qualidade média $(u)$. Pelo lado da oferta, a qualidade média, bem como a quantidade ofertada de carros usados, também são funções do preço. Logo, o preço é o sinalizador de escassez e de qualidade das mercadorias. Se o preço cai, diminui a qualidade. Como visto, Chamberlain (1953) relaciona o preço com a variação qualitativa dos produtos e Stiglitz (1987) utiliza explicitamente o preço como sinalizador da qualidade.

O tratamento teórico e formal predominante na microeconomia não concebe a variável preço relacionada com outras duas. O preço costumeiramente apenas sinaliza a escassez e determina a quantidade demandada e ofertada de acordo com as preferências prévias e estáveis de consumo. Há um desafio teórico e metodológico de relacionar o preço com a qualidade e a quantidade ao mesmo tempo, considerando a instabilidade das preferências ante as inovações de produto, o aprendizado de consumo de indivíduos socializados e as respectivas desorganizações das convenções de valoração das mercadorias. As relações fuzzy parecem ser um instrumental adequado para auxiliar nesta empreitada. No exercício a seguir, explora-se a relação do preço com a qualidade.

Uma Relação Fuzzy ${ }^{5}$ é definida a partir do produto cartesiano de dois conjuntos fuzzy. Um conjunto fuzzy está inserido em um conjunto universo unidimensional. Já uma relação fuzzy é um conjunto fuzzy em um espaço multidimensional, ou seja, é um conjunto que perpassa dois ou mais conjuntos universo. O espaço multidimensional é definido pelo produto Cartesiano (TANAKA, 1997; BOJADZIEV \& BOJADZIEV, 1995).

O produto Cartesiano de dois subconjuntos fuzzy $A$ e $B$ relativos aos conjuntos universo $U_{1}$ e $U_{2}$, respectivamente, é

$A \times B=\{(x, y) \mid x \in A, y \in B\}$.

A relação fuzzy em $A \times B$ é identificada por $R$ e definida pela expressão

$$
R=\left\{\left((x, y), \mu_{R}(x, y)\right) \mid(x, y) \in A \times B, \mu_{R}(x, y) \in[0,1]\right\},
$$

\footnotetext{
${ }^{5}$ Uma tradução livre de fuzzy relation é "relação difusa". Fuzzy sets, no mesmo padrão, seria "conjuntos difusos". No entanto, a combinação da denominação em inglês fuzzy com o substantivo "conjuntos" formando a expressão "conjuntos fuzzy" já é de uso comum no Brasil. Por analogia, utiliza-se neste texto "relação fuzzy".
} 


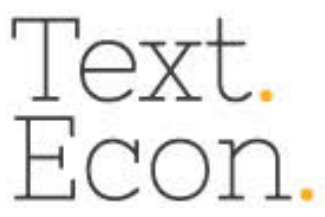

na qual $\mu_{R}(x, y)$ é uma função de pertinência em duas variáveis. Esta função associa a cada par ordenado $(x, y)$ em $A \times B$ um número real no intervalo [0,1]. A pertinência indica o grau pelo qual $x$ está relacionado a $y$ (BOJADZIEV \& BOJADZIEV, 1995, p. 141). No caso em discussão, as relações linguísticas retratadas ocorrem em dois sentidos: $a$ ) o quanto a variação da qualidade $x$ é relevante para a variação do preço $y$, e $b$ ) o quanto a variação do preço $y$ sinaliza variação de qualidade $x$.

A união entre duas relações fuzzy $R_{1}$ e $R_{2}$ é retratada por $R_{1} \cup R_{2}$ e definida por

$\mu_{R 1 \cup R 2}=\max \left\{\mu_{R 1}(x, y), \mu_{R 2}(x, y)\right\},(x, y) \in A \times B$.

Outras operações são possíveis com relações fuzzy, tais como intersecção, complementaridade e inclusão.

\subsubsection{Projeções de relações fuzzy}

Considere uma relação fuzzy

$$
R=\left\{\left((x, y), \mu_{R}(x, y)\right) \mid(x, y) \in A \times B, \mu_{R}(x, y) \in[0,1]\right\} .
$$

A projeção equivale à incidência de luz que projeta uma sombra sobre o eixo $x$ ou $y$.

A primeira projeção de $R$ em $x$ é definida como

$$
R^{(1)}=\left\{\left(x, \mu_{R^{1}}(x, y)\right)\right\}=\left\{(x, \underbrace{\max }_{y} \mu_{R}(x, y)) \mid(x, y) \in A \times B\right\} .
$$

Na expressão acima, $\underbrace{\max }_{y}$ significa máximo com respeito à $y$ e projetado em $x$.

A projeção de $R$ em $y$ é

$$
R^{(2)}=\left\{\left(y, \mu_{R^{1}}(x, y)\right)\right\}=\left\{(y, \underbrace{\max }_{x} \mu_{R}(x, y)) \mid(x, y) \in A \times B\right\} .
$$

Na expressão acima, $\underbrace{\max }_{x}$ significa máximo com respeito à $x$ e projetado em $y$.

Por fim, a projeção total é definida como

$$
R^{(T)}=\underbrace{\max }_{x} \underbrace{\max }_{y}\left\{\mu_{R}(x, y) \mid(x, y) \in A \times B\right\} .
$$

A projeção total permite identificar o ponto de máxima pertinência do conjunto fuzzy representado pela relação fuzzy em $A \times B$.

Diferentes relações fuzzy podem ter a mesma projeção $R^{(1)}$ ou $R^{(2)}$. Chama-se de extensão cilíndrica a expansão para todas as colunas ou todas as linhas da projeção $R^{(1)}$ ou 


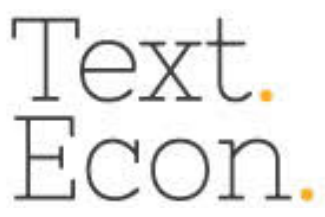

$R^{(2)}$, e representada por $c\left(R^{(1)}\right)$ e $c\left(R^{(2)}\right)$, respectivamente. O valor projetado é o de maior pertinência $(\mu)$ da coluna ou da linha, estando os valores inferiores que compõe o conjunto fuzzy nela contidos. A relação original está contida na extensão cilíndrica, $R^{1} \leq c\left(R^{(1)}\right)$ e $R^{2} \leq c\left(R^{(2)}\right)$. O Exemplo 1 apresenta projeções e as respectivas extensões cilíndricas.

Exemplo 1 - Considere a seguinte relação fuzzy $R$.

\begin{tabular}{r|ccc}
$R=x_{1}$ & $\frac{y_{1}}{y_{2}}$ & $\frac{y_{2}}{1}$ & [a] \\
$x_{2} \mid$ & 0,5 & 0,2
\end{tabular}

A projeção de $R^{(1)}$ em relação a $x$ fica

$\frac{R^{(1)}}{1}[\mathrm{~b}]$

0,5

A extensão cilíndrica da projeção de $R$ em $x$ é

$c\left(R^{(1)}\right)=$\begin{tabular}{c|ccc}
$x_{1}$ & $\frac{y_{1}}{1}$ & $\frac{y_{2}}{1}$ & \\
$x_{2} \mid$ & 0,5 & 0,5 &
\end{tabular}

Para a mesma relação fuzzy [a]

$R=$\begin{tabular}{r|ccc} 
& $\frac{y_{1}}{x_{1}}$ & $\frac{y_{2}}{1}$ & \\
$x_{2}$ & 0,6 & 0,5 & 0,2
\end{tabular}$\quad[\mathrm{a}]$,

A projeção de $R^{(2)}$ em relação a $y$ fica

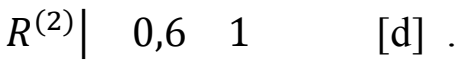

A extensão cilíndrica da projeção de $R$ em $y$ é

$\begin{array}{rll}c\left(R^{(2)}\right)=x_{1} \mid & \frac{y_{1}}{} & \frac{y_{2}}{1} \\ x_{2} \mid & 0,6 & 1\end{array}$

A projeção total do exemplo é

$R^{(T)}=1$ [f] 


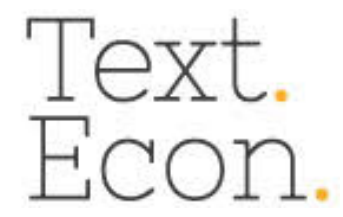

\section{MÉTODO E RESULTADOS DO EXERCÍCIO}

Há alguns pressupostos não-convencionais no tratamento proposto para captar a relação entre preço e qualidade da mercadoria, desenvolvido a seguir.

a) A qualidade da mercadoria não é evidente e igual para todos os produtores e usuários;

b) As mercadorias proporcionam serviços de diferentes naturezas e proporções cuja apreensão varia de acordo com a percepção individual;

c) A avaliação de qualidade pelo consumidor manifesta-se no preço a pagar.

Há muito está manifesta uma discordância teórica fundamental entre os economistas acerca da representação do comportamento dos agentes. A visão dominante supõe um sujeito que decide com racionalidade substantiva. Para outros ${ }^{6}$, os indivíduos - consumidores ou unidade produtiva com autonomia decisória - não captam e processam um elevado conteúdo informacional e tampouco decidem de maneira ótima.

Nesta perspectiva crítica ao neoclassicismo, Van Kooten et alli (1986) admitiram que os decisores perseguem múltiplos objetivos, e que tentam satisfazê-los simultaneamente; introduziram a modelagem com os conjuntos fuzzy para permitir que os respondentes (em seu trabalho, agricultores) ordenassem o grau de preferência para os diversos objetivos. Em seu estudo, a fim de coletar a informação de preferência entre dois atributos A e B, o respondente assinalava sobre uma linha traçada em um questionário se era indiferente (neutro), se preferia A ou se preferia B. A distância em relação ao ponto de indiferença dava a magnitude da preferência.

Figura1 - Abordagem fuzzy para comparações aos pares entre itens A e B

A

Fonte: Van Kooten et alii (1986)

$\mathrm{Na}$ consecução do presente artigo utilizou-se a linha traçada no papel como canal de comunicação da percepção de qualidade dos consumidores de carne. Inspirada em Van

\footnotetext{
${ }^{6}$ Aqui há muitas correntes. Além das abordagens de perceived quality e means-end chain, já mencionadas, existem outras visões de sujeito econômico entre os institucionalistas veblenianos e evoluciocionários.
} 


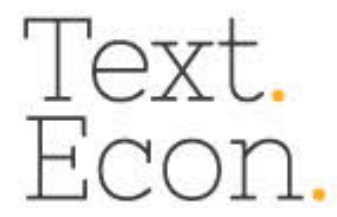

Kooten et alli (1986), a concepção e organização da informação, no entanto, ganhou contornos peculiares que diferem da empregada por eles.

\subsection{Procedimentos}

O trabalho iniciou pela aplicação de um pequeno questionário dirigido a consumidores de carne abordados em supermercados e açougues na cidade de Santa Maria, estado do Rio Grande do Sul, Brasil.

Primeiramente, inquiria-se se o respondente apreciava e consumia picanha bovina e logo após se solicitava que ele indicasse, livremente, intervalos para as qualidades boa, média e ruim sobre uma linha horizontal de 10 centímetros traçada em uma folha de papel. A linha representava um gradiente de cor de carne tendo no extremo esquerdo "vermelho escuro" e no extremo direito "vermelho claro e vivo". O respondente assinalava três intervalos sobre a linha: $a$ ) um intervalo para a qualidade boa, $b$ ) um intervalo para a qualidade média e $c$ ) outro intervalo para a qualidade ruim.

Figura 2 - Régua de percepção de atributos de qualidade

\begin{tabular}{|ll|}
\hline Vermelho Escuro __ Vermelho Claro \\
\end{tabular}

Fonte: autores

Concluída a indicação dos intervalos, perguntava-se se ele considerava os limites entre os intervalos precisos ou aproximativos. Encerrando a inquirição sobre o conjunto "cor da carne", propunha-se um preço de $\mathrm{R} \$ 10,00 / \mathrm{Kg}$ para o intervalo de cor média por ele assinalado e perguntava-se o quanto pagaria por um quilograma de carne de cor boa e, também, por um quilograma de carne de cor ruim, considerando variação unitária no preço e tendo por limite superior e inferior $\mathrm{R} \$ 20,00$ e $\mathrm{R} \$ 0,00$, respectivamente ${ }^{7}$.

$\mathrm{O}$ mesmo procedimento repetiu-se com cada respondente para os conjuntos "maciez da carne" e "teor de gordura", respectivamente, tendo no ponto extremo esquerdo da linha de 10 centímetros o sinal “- " (menos macia ou menor teor de gordura) e no extremo direito o sinal “+”(mais macia e maior teor de gordura). Logo a seguir, sempre era proposto o preço de

\footnotetext{
${ }^{7}$ As informações foram coletadas em meados de 2012. As restrições de variação unitária e limite superior de preço faziam sentido com uma fórmula linear da relevância da variação da qualidade para variações nos preços. Com a fórmula exponencial utilizada neste artigo, tal limitação foi superada.
} 


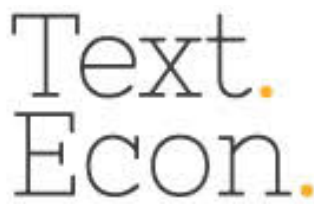

$\mathrm{R} \$ 10,00 / \mathrm{Kg}$ para o conjunto de qualidade média e investigada a disposição a pagar para a qualidade boa e para a qualidade ruim.

Houve vinte e quatro respondentes cujas respostas foram processadas utilizando relações fuzzy.

$5.2 \mathrm{O}$ grau de relevância da qualidade para o preço $\left(\mu_{R}(x, y)\right)$

O exercício objetiva retratar pela ótica do consumidor a relevância de características qualitativas para o estabelecimento do preço que ele está disposto a pagar.

Uma mercadoria possui diversas características qualitativas que proporcionam "serviços" para a satisfação de desejos ou percepções sensoriais dos consumidores (WITT, 2001). Uma particular necessidade pode ser atendida pelo consumo de diferentes mercadorias ou diferentes combinações de mercadorias; por outro lado, o consumo de uma mercadoria pode atender diversas necessidades simultaneamente (WITT, 2016).

Cada consumidor pode possuir outra percepção da mercadoria. Os elementos que deseja podem ser distintos de outras pessoas e, mesmo que sejam idênticos, as apreensões sensoriais do objeto não são necessariamente iguais. Por fim, a importância de cada elemento, manifesta pela disposição a pagar por um incremento de qualidade, também varia entre indivíduos.

Uma característica pode satisfazer parcialmente diferentes desejos simultaneamente; combinada com uma outra característica, ambas podem potencializar a sua capacidade de responder a um desejo que isoladamente cada uma minimamente atenderia.

Estes aspectos fazem com que a relação qualidade-preço seja complexa e convenientemente retratada como uma matriz de relações fuzzy na qual as linhas representam a variação percentual em três características de qualidade de carne, a saber - cor, maciez e teor de gordura-, cada característica composta por três subconjuntos de variação qualitativa - boa, média e ruim -.

Cada subconjunto qualitativo foi encarado como um número fuzzy triangular. A função de pertinência triangular de uma característica de qualidade $x$ é descrita como segue: 


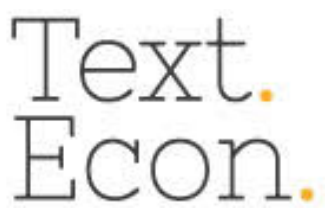

$\mu_{A}(x)\left\{\begin{array}{c}0, \quad x \leq \rho_{\text {min }} \\ \frac{x-\rho_{\min }}{c-\rho_{\min }}, x \in\left(\rho_{\min }, c\right) \\ \frac{\rho_{\max }-x}{\rho_{\max }-c}, x \in\left(c, \rho_{\max }\right) \\ 0, x \geq \rho_{\max }\end{array}\right.$

sendo os valores de dispersão mínimo $\rho_{\min }$ e máximo $\rho_{\max }$, respectivamente, e o parâmetro $c$ o centro ou valor modal da função.

Todos os respondentes informaram entenderem os limites entre os intervalos de qualidade como aproximativos. Interpretou-se a linha de 10 centímetros como uma linha de ambivalência ao conjunto de qualidade boa, média ou ruim retratado, ou seja, de grau de pertencimento $\mu=0,5$ ao conjunto $A$ definido pelo adjetivo boa, média ou ruim. Isto significa que os valores assinalados pelo respondente foram utilizados como os valores de dispersão sobre um valor de corte $(\alpha c u t)$ de 0,5 de pertinência ao conjunto qualitativo retratado. Eles são o mínimo $\rho_{\min }$ e máximo $\rho_{\max }$ e permitem obter o parâmetro $c$, ou seja, um valor em centímetros projetado sobre a linha correspondente ao ponto no qual $\mu_{A}(x)=1$. Os pontos correspondentes a $\mu_{A}(x)=0$ resultam de extrapolação através das funções lineares do número triangular. A seguir está representada a resposta de um entrevistado assinalada sobre a linha de $10 \mathrm{~cm}$ e o número fuzzy triangular obtido.

Figura 3 - Relação entre a Régua de percepção de atributos e número triangular fuzzy

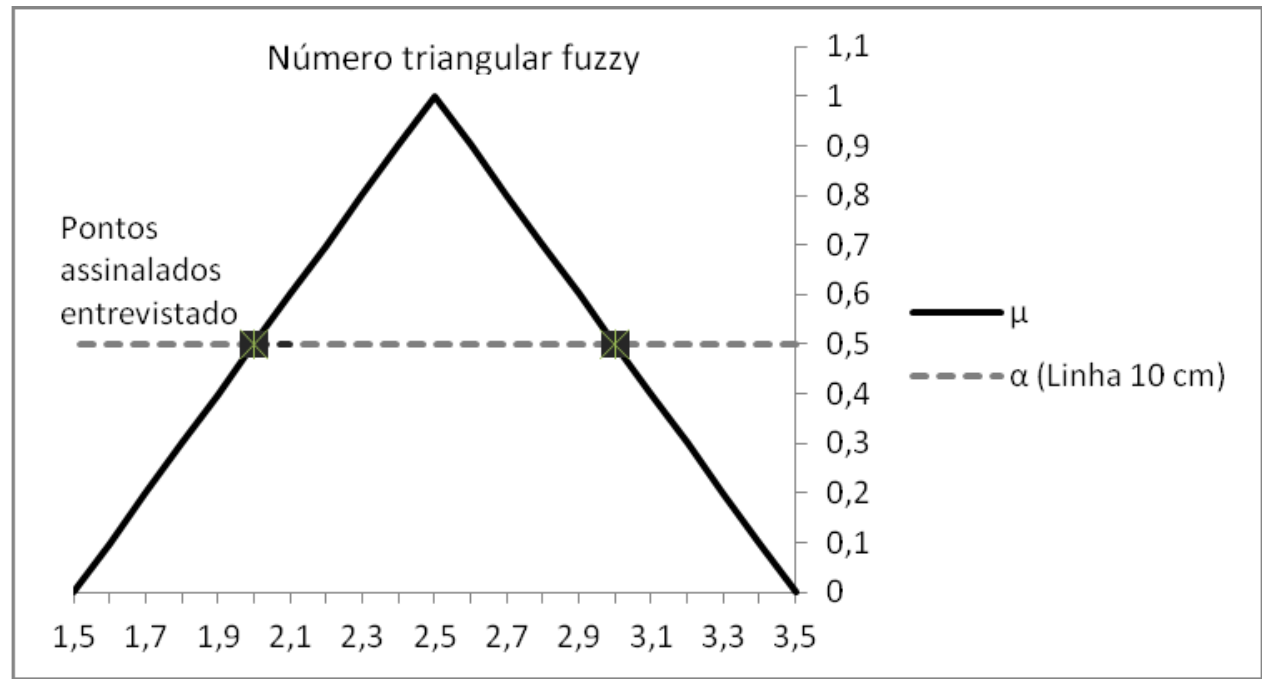

Fonte: autores 


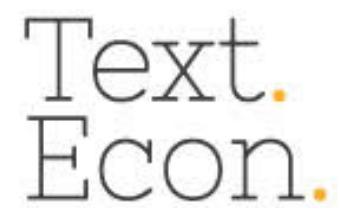

Para a variação de qualidade de média para boa, o grau de relevância da qualidade $x$ para o preço $p$ é calculado pela seguinte fórmula

$$
\mu_{R}(x, y)=\frac{((p \text { cor boa })-(p \text { cor média }))}{(p \text { cor boa })}\left(\frac{1}{\text { corboa-cor média })}\right),
$$

para $p$ cor média $=10$, e $p$ cor boa $\geq 11$ com variação unitária.

O valor de $\mu_{R}(x, y)$ vai de 0 , sem relevância, para 1 , conforme aumenta a relevância da variação da qualidade para a variação do preço.

Efetuaram-se duas inferências. A primeira com a variação de qualidade média para qualidade boa e a respectiva repercussão na variação dos preços. A segunda com a variação de qualidade média para qualidade ruim e sua relação com a variação nos preços. Utilizou-se para tanto o software Excel 2010.

\subsection{A matriz qualidade-preço}

A relação entre a variação da qualidade da mercadoria carne e a variação do preço a pagar foi expressa em uma matriz numérica. As linhas representam a variação qualitativa relativa da mercadoria e as colunas a variação do preço a pagar.

A variação de uma qualidade de média para boa (ou para ruim) foi representada por $x_{1}$ para a variação de cor, $x_{2}$ para a variação de maciez e $x_{3}$ para a variação de teor de gordura. Cara variação de característica tem dez gradientes, ou seja, apresenta dez linhas $l$, com

$$
l=1,2,3,4,5,6,7,8,9,10 .
$$

Assim, a variação de cor média para boa (ou ruim) apresenta as linhas $x_{11}, x_{12}, \ldots, x_{19}, x_{110}$. A variação da maciez média para boa (ou ruim) tem como linhas $x_{21}, x_{22}, \ldots, x_{29}, x_{210}$. E, por fim, a variação de teor de gordura de médio para bom (ou ruim) é dada por $x_{31}, x_{32}, \ldots, x_{39}, x_{310}$.

A linha correspondente à variação relativa de qualidade de cor média para boa é exemplificada a seguir pela equação

$$
x_{1 l}=\left(\left(\left(\mu=1_{\text {cor boa }}\right)-\left(\mu=1_{\text {cor média }}\right)\right) \div\left(\mu=1_{\text {boa }}\right)\right)
$$

Para as demais características de qualidade, maciez e teor de gordura, o procedimento é análogo. Para as variações de qualidade média para ruim seguiu-se o mesmo método, sempre utilizando o $\mu$ de maior valor como base para a variação. 


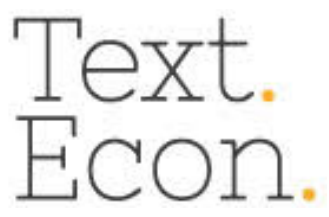

Nas colunas tem-se a variação do preço da mercadoria correspondente a uma variação na qualidade de uma característica. Por exemplo, quanto varia a disposição a pagar quando a qualidade da cor varia de média para boa?

No topo da matriz de cálculo da relevância da qualidade para o preço $\mu_{R}(x, y)$, as primeiras dez colunas tem por título a variação do preço de cor média para a cor boa (ou ruim) $\left(y_{1}\right)$, seguida por dez colunas da variação do preço da maciez média para maciez boa (ou ruim) $\left(y_{2}\right)$ e da variação de preço para a alteração do teor de gordura de médio para teor bom (ou ruim) $\left(y_{3}\right)$. A variação de preço de cada característica está subdividida em um gradiente de dez colunas $k$. Assim, a variação do preço da cor de média para boa (ou ruim) apresenta as colunas $y_{11}, y_{12}, \ldots, y_{19}, y_{110}$. A variação de preço da maciez de média para boa (ou ruim) tem como colunas $y_{21}, y_{22}, \ldots, y_{29}, y_{210}$. E, finalmente, a variação de preço do teor de gordura de médio para bom (ou ruim) é dada por $y_{31}, y_{32}, \ldots, y_{39}, y_{310}$.

Exemplificando novamente com a variação de cor de média para boa, a coluna correspondente à variação de preço de cor média para boa denotada pelo respondente é obtida pela equação

$$
y_{1 c}=\frac{\left(p_{b}-p_{m}\right)}{p_{b}}, k=1 \ldots 10,
$$

com $p_{b}$ para preço da cor boa e $p_{m}$ para preço da cor média.

Para obter o grau de relevância $\mu_{R}(x, y)$ para a relação preço e qualidade, processouse cada resposta individual acerca de uma mudança de característica de boa para média, conforme a equação [8]. O resultado foi ponderado de forma a ressaltar a possibilidade de efeitos cruzados das diferentes características de qualidade sobre a disposição a pagar. Exemplificando, o preço a pagar pela cor é primeira e fortemente influenciado pela percepção do cliente da cor da carne (peso 0,80$)^{8}$ e secundária e complementarmente afetado pela maciez (peso 0,10) e pelo teor de gordura (peso 0,10) para os quais, inclusive, a cor pode ser um indicador, conforme avaliação individual do consumidor.

O Exemplo 2 apresenta os principais elementos da inferência.

Exemplo 2 - Relevância da cor para o preço, qualidade de cor média a boa.

\begin{tabular}{|lccc|}
\hline $\begin{array}{l}\text { Ponto do intervalo } \\
\text { na linha } 10 \mathrm{~cm}\end{array}$ & $\begin{array}{c}\text { Mínimo } \\
(\mathrm{cm})\end{array}$ & $\begin{array}{c}\text { Máximo } \\
(\mathrm{cm})\end{array}$ & $\begin{array}{l}\mu=1 \\
(\mathrm{~cm})\end{array}$ \\
\hline cor boa & 7,6 & 10 & 8,8 \\
\hline cor média & 3,3 & 7,2 & 5,25 \\
\hline $\begin{array}{l}\text { preço cor boa } \\
(p b)\end{array}$ & $\mathrm{R} \$ 13 / \mathrm{Kg}$ & & \\
$\begin{array}{l}\text { preço cor média } \\
(p m)\end{array}$ & $\mathrm{R} \$ 10 / \mathrm{Kg}$ & & \\
\hline
\end{tabular}


A projeção total $R^{(T)}$ será utilizada a seguir como um indicador para comparar a relevância da qualidade para o preço entre diferentes inferências. A fim de tornar a comparação mais robusta, complementa-se com uma segunda medida que consiste na soma dos graus de relevância da matriz de união das respostas de todos os respondentes para cada inferência, representada por $\left(\operatorname{soma\mu }_{(x y)}\right)$.

5.4 A relevância da variação de qualidade para variações nos preços

As relações fuzzy $R$, de cada um dos vinte e quatro entrevistados, foram unidas utilizando o operador max, conforme a equação [3] (p. 13). Inicialmente foi efetuada a inferência para a variação de qualidade média para boa e sua relevância para a variação nos preços. A seguir, inferiu-se a relevância da qualidade média para ruim e sua relevância para os preços. Ambas foram comparadas.

Projetou-se o resultado da união das respostas dos entrevistados sobre os eixos $x$ e $y$, obtendo respectivamente $R^{(1)}$ e $R^{(2)}$. Calculou-se, ainda, as extensões cilíndricas e $c\left(R^{(1)}\right)$ e $c\left(R^{(2)}\right)$ e a Projeção total $R^{(T) 9}$, analogamente ao apresentado no Exemplo 1 . Complementarmente a $R^{(T)}$, a fim de aumentar a robustez da análise, calculou-se o somatório dos graus de relevância da matriz $\left(\operatorname{soma\mu }_{(x y)}\right)$.

Para a variação de qualidade média a boa e sua repercussão nos preços, $R^{(T)}=0,37$ e $\operatorname{soma\mu }_{(x y)}=5,47$.

Para a variação de qualidade média a ruim e sua repercussão nos preços, $R^{(T)}=1 \mathrm{e}$ $\operatorname{soma\mu }_{(x y)}=22,05$.

\footnotetext{
${ }^{9}$ Os gráficos relativos à inferência e as projeções sobre os eixos podem ser requeridos diretamente aos autores. A disponibilidade de espaço limita a sua inserção no artigo.
} 


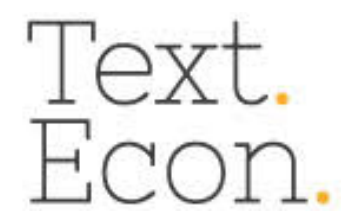

A relevância da variação de qualidade média para ruim para os preços é maior comparativamente à relevância da variação de qualidade média para boa para os preços.

5.2.2 A relevância da variação dos preços para variações na qualidade

Embora a ordem das perguntas no questionário leve em consideração a relevância da qualidade para a formação do preço, a literatura concebe que os consumidores tomem o preço como um indicador de qualidade. A seguir, esta possibilidade é explorada pela inversão entre base e expoente na fórmula do grau de relevância, ou seja, a variação de preços será o expoente e, em tese, exerce influência sobre a variação de qualidade.

$$
\mu_{R}(x, y)=\frac{((\text { cor boa })-(\text { cor média }))}{(\text { cor boa })}\left(\frac{\frac{1}{p \text { cor boa }- \text { p cor média })}}{p \text { cor boa }}\right) \times 0,80
$$

Para a variação de preços e sua repercussão na qualidade média a boa, $R^{(T)}=0,76 \mathrm{e}$ $\operatorname{soma\mu }_{(x y)}=8,93$.

Por fim, apresentam-se os resultados para a relevância das variações de preços para a variação de qualidade média a ruim.

Para a variação de preços e sua repercussão na qualidade média a ruim, $R^{(T)}=0,92 \mathrm{e}$ $\operatorname{soma\mu }_{(x y)}=25,79$.

A variação dos preços foi mais relevante para as variações de qualidade de média para ruim do que para a variação de qualidade média para boa,

\section{CONSIDERAÇÕES FINAIS}

A exposição não exaustiva de esforços de economistas rediscutindo o preço à luz de aspectos qualitativos indica que houve esforços de revisão teórica que implicaram ligar o preço tanto à escassez da mercadoria como com a sua qualidade. $\mathrm{O}$ avanço de compreensão dos processos de escolha dos consumidores foi restringido pela obsessão em estabelecer o preço de mercado e pela vinculação ao instrumental matemático de variações infinitesimais.

O exercício efetuado implicou o deslocamento do objeto de mensuração. Em lugar de encontrar o preço de equilíbrio do consumidor (ou do mercado), buscou-se compreender o processo de valorização da qualidade da mercadoria através dos preços por intermédio de uma medida da relevância da variação de qualidade para os preços e, alternativamente, de medida 


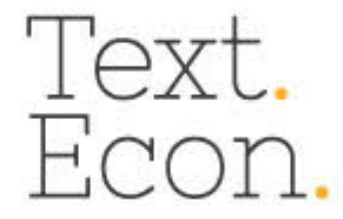

de variação dos preços como sinalização de qualidade. O caminho seguido neste exercício prescinde do uso de fortes pressupostos sobre a disponibilidade das informações de preço e qualidade, bem como sobre o comportamento e capacidades decisórias dos agentes econômicos, elementos inerentes às formulações vinculadas aos modelos de variações infinitesimais.

A discussão teórica desenvolvida aponta para que as propensões de consumo e o processo de concorrência entre as firmas devam constituir um corpo teórico integrado a fim de que se capte a riqueza do processo de evolução qualitativa das mercadorias. Por um lado, as firmas criam novos atributos e incrementam antigos, concorrendo umas com as outras tentando captar ou fomentar interesses em seu público-alvo e, por outro, os consumidores, provocados pelas firmas ou emulando padrões de comportamento, projetam sobre as mercadorias novos significados e evoluem nas suas valorações. Os consensos efêmeros de mercado resultam deste embate. Abordagens que evitam a interação entre agentes, talvez por não considerá-las objeto da Economia - e estabelecem unicamente uma relação entre o agente decisor individual e objeto material -, têm dificuldade de compreender e mensurar a incessante criação de variação qualitativa dentro dos sistemas econômicos contemporâneos.

Procurou-se argumentar que a avaliação da qualidade das mercadorias - associada aos seus $n$ atributos- e a eventual objetivação dessa qualidade em um preço derivam de cognições humanas; os indivíduos sofrem diversos tipos de pressão sociocultural e psicológica, fatores seletivos para a suas avaliações e escolhas. A diversidade de atributos qualitativos e a assimetria de conhecimento e de informação tornam a avaliação da relação entre preço e qualidade substancialmente incerta, impedindo que se efetue um cálculo de risco provável acerca da qualidade das mercadorias e o preço, digamos, compatível com ela.

Embora simples, o exercício aqui proposto procurou contribuir analiticamente para retratar o resultado do processo decisório, pautado pelas percepções dos consumidores sobre a variação da qualidade e suas disposições de pagar determinado preço na compra de um produto alimentar menos complexo (um determinado corte de carne - a picanha). Para tanto, assumiu-se que essas avaliações tendem a ser efetuadas de forma verbal através de classificações graduais e não de forma binária. Nesse sentido, recorreu-se à teoria dos conjuntos fuzzy, que permite a aproximação da linguagem lógica e matemática da linguagem cotidiana.

O resultado do exercício converge para a ideia de o preço ser indicador de qualidade das mercadorias. Comparando os dois sentidos da inferência de: i) qualidade média-ruim para 


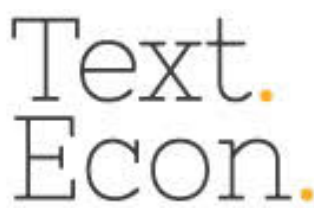

$\operatorname{preços}\left(R^{(T)}=1\right.$ e $\left.\operatorname{soma} \mu_{x y}=22,05\right)$; e, ii) dos preços para a qualidade média-ruim $\left(R^{(T)}=\right.$ 0,92 e $\left.\operatorname{soma}_{x y}=25,79\right)$, a relevância é bastante próxima segundo os dois indicadores utilizados. Diferentemente, comparando-se: iii) qualidade média-boa para preços $\left(R^{(T)}=0,37\right.$ e $\left.\operatorname{soma} \mu_{x y}=5,47\right)$; e iv) dos preços para a qualidade média-boa $\left(R^{(T)}=0,76\right.$ e $\operatorname{soma} \mu_{x y}=$ 8,93), o preço é mais relevante para as variações de qualidade.

Considerando as percepções de variação de qualidade do produto em questão e suas relações interativas com a disposição de compra dos consumidores e com a mudança do preço desse produto, os resultados do exercício empírico mostraram que:

a) a variação de uma qualidade média para uma ruim mostrou-se mais relevante para as variações nos preços que os consumidores estão dispostos a pagar comparativamente à variação de uma qualidade boa para a média. A hipótese que emerge é de que os consumidores prestam mais atenção ao preço quando a qualidade adentra parâmetros por eles considerados ruins;

b) a variação do preço também mostrou maior relevância para a variação de qualidade média para a ruim comparativamente a variação de qualidade média para a boa; ou seja, considerando o conjunto de opiniões dos consumidores, a variação do preço poderia ser interpretada como um indicador para alertar para a qualidade ruim do produto. $\mathrm{O}$ preço como indicador de qualidade ruim ecoa os dizeres de Chamberlain (1953, 3-6), que afirmou que o desejo de manter o padrão de qualidade dos produtos é uma explicação da aversão dos homens de negócios à guerra de preços; os consumidores percebem a redução dos preços inerentes às guerras de preços como uma redução de qualidade dos produtos e trocam suas opções de compras. Como se efetuou apenas um exercício, avaliações mais representativas neste e em outros produtos são necessárias.

O método apresentado não tem aplicação limitada a produtos agroindustriais. É um instrumento direto de acesso à disposição a pagar dos consumidores por certo produto, considerando as suas percepções de qualidade-preço ou vice-versa.

Evidentemente que esta versão básica do exercício empírico pode ser metodologicamente mais aprimorada, por exemplo, realizando a comparação da relação entre qualidade e preço entre diferentes mercadorias e entre grupos com características comportamentais definidas; ou, analisando a combinação da variação qualitativa com a variação quantitativa das mercadorias e a relação de ambas com o preço. Há diversas 


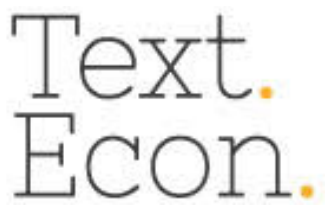

possibilidades empíricas abertas, tanto para os estudiosos do tema, bem como para empresas que desejam conhecer melhor o mercado em que atuam.

\section{REFERÊNCIAS BIBLIOGRÁFICAS}

AKERLOF, George A.. The market for "lemons": quality uncertainty and the market mechanism”. The Quarterly Journal of Economics, Vol. 84, p. 488-500, 1970.

BOJADZIEV, George; BOJADZIEV, Maria. Fuzzy sets, fuzzy logic, applications. Singapore: World Scientific Publishing, 1995.

BRUNSO, Karen; FJORD, Thomas A.; GRUNERT, Klaus G.. "Consumer' food choice and quality perception”. The Aarhus School of Business. Working Paper, p. 1-60, 2002.

COESTIER, Bénédicte; MARETTE, Stéphan. Economia da qualidade. São Paulo: Senac, 2009.

CHAMBERLAIN, Edward H.. The Product as an Economic Variable. The Quaterly Journal of Economics, 67 (1), 1-29, 1953.

DARBY, Michael R.; KARNI, Edi. Free competition and the optimal amount of fraud. Journal of Law and Economics, N. 16, p. 67-88, 1973.

HALL, R. L.; HITCH, C. J. A teoria dos preços e o comportamento empresarial. Literatura econômica IPEA, 8(3), 1986.

HIRSCHMAN, Albert. Saída, Voz e Lealdade: reações ao declínio de firmas, organizações e estados. São Paulo: Perspectiva, 1973.

KOUTSOYIANNIS, Anna. Non-Price Decisions: The Firm in a Modern Context. Hong Kong: The Macmillan Press Ltd., 1982.

LUPTON, Sylvie. Quality uncertainty in early economic thought. History of Political Economy, 47, p. 511-34, 2015.

MARTINELLI JÚNIOR, Orlando; ROHENKOHL, Júlio; MURAKAMI, Thays. Technology and Innovation on Input Sectors of Brazilian Meat Production. Journal of Economics and Development Studies, v. 2, p. 185-2001, 2014.

SCITOVSKY, Tibor. Some Consequences of the Habit of Judging Quality by Price. The Review of Economic Studies, 12 (2), 1944.

SRAFFA, P. As Leis dos Rendimentos sob Condições de Concorrência. Literatura Econômica IPEA, 4 (1), 1982.

STEINDL, Josef. Maturidade e estagnação no capitalismo americano. São Paulo: Abril, 1983. 


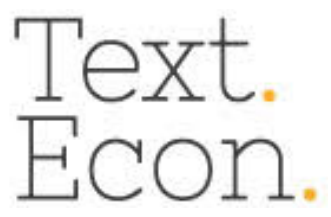

STIGLITZ, Joseph E.. The Causes and Consequences of the Dependence of Quality on Price. Journal of Economic Literature, v. 24, p.1-48, 1978.

TANAKA, Kazuo. An introduction for fuzzy logic for practical applications. New York: Rassel, 1997.

VALETTE-FLORENCE, Pierre. A causal analysis of means-end hierarchies in a cross cultural context: Methodological refinements. Journal of Business Research, 42, p. 161-66, 1998.

VAN KOOTEN, G.C.; SCHONEY, Richard A.; HAYWARD Keith A.. An alternative approach to the evaluation of goal hierarchies among farmers. Western Journal of Agricultural Economics, 11, p. 40-49, 1986.

WITT, Ulrich. Learning to consume - A theory of wants and the growth of demand. Journal of Evolutionary Economics, v. 11, p. 23-36, 2001.

WITT, Ulrich. The evolution of consumption and its welfare effects. Journal of Evolutionary Economics, p. 1-21, 2016. Accessed August 23, 2016. doi:10.1007/s00191-016-0459-3.

ZADEH, Lotfi A.. Fuzzy Sets. Information and Control, 8, p. 338-53, 1965.

ZIMMERMANN, Hans-J.. Fuzzy Set Theory and Its Applications. Norwell: Kluwer Academic Publishers, 1991. 